\title{
Public Sphere, Linguistic Sphericules and Discourse Communities in Africa
}

\author{
Théophile Ambadiang*
}

\begin{abstract}
Discourse, as seen in Habermas's definition of the public sphere, is an essential aspect of the participation of the citizenry in the public debate which, crucially, is supposed to take place in a linguistically homogeneous society. The aim of this paper is to discuss the centrality of discourse in Habermas's theory in a genuinely multilingual context as is sub-Saharan Africa. We intend to show that the discursive practices and, more generally, the complex dynamics that characterize public debate in this context are determined by sociolinguistic factors such as 'elite closure', linguistic repertoire, as well as by social exclusion (Scotton 1993). Elite closure, considered as social exclusion based on linguistic competence, has had the effect of constructing a public sphere around a specific version of the European (official) language, as it excludes the majority of the citizenry who makes use of the popular versions of these languages. The correlation that exists between visibility (in the public sphere) and register repertoire accounts for the uniformity or homogeneity in the register that tends to characterize public debates, as even individuals who typically use the popular versions of the European languages adopt the register of the elite (often with undesired effects). Language, thus, divides the public sphere in smaller groups along the lines of register competence as well as of linguistic competence which excludes those who have no knowledge of the European official language. This study further suggests that those groups or sphericules (Gitlin 1998) constitute discourse communities in the sense of Watts (1999), that is, sets of individuals whose discourse practices reveal common interests, goals and beliefs. Lastly, we argue that the visibility of all such groups requires the openness of the public sphere to diverse discourses (Fairclough 1999, 2006), independently of the way they materialize. In this sense, the contribution of the individuals whose linguistic repertoires do no include European languages will not necessarily nor exclusively be framed in linguistic terms. One interesting consequence of the discussion is the disempowering/disempowerment of the (European) languages in the African public sphere.
\end{abstract}

* Universidad Autónoma de Madrid, C/Monsalupe 16ab;b, Madrid 28047, Spain. E-mail: theophile.ambadiang@uam.es 


\section{Résumé}

Dans la définition de Habermas de la sphère publique, le discours est considéré comme un aspect essentiel de la participation des citoyens au débat public qui, fondamentalement, est censé se dérouler dans une société linguistiquement homogène. Le but de cet article est d'évaluer la centralité du discours dans la théorie d'Habermas dans un contexte multilingue comme l'Afrique subsaharienne. Nous nous proposons de montrer que les pratiques discursives, et plus généralement la dynamique qui caractérisent le débat public dans ce contexte, sont déterminées par des facteurs sociolinguistiques tels que la "fermeture de l'élite », le répertoire linguistique, ainsi que par l'exclusion sociale (Scotton, 1993). La fermeture de l'élite, considérée comme l'exclusion sociale basée sur la compétence linguistique, a eu pour effet de construire une sphère publique autour d'une version spécifique des langues européennes (officielles), car elle exclut la majorité des citoyens qui utilisent des versions populaires de ces langues. La corrélation entre la visibilité (dans la sphère publique) et le répertoire de registres rend compte de l'uniformité ou de l'homogénéité du registre qui caractérise généralement les débats publics, puisque même les personnes qui utilisent généralement les versions populaires des langues européennes adoptent le registre de l'élite (souvent avec des effets indésirables). La langue divise ainsi la sphère publique en petits groupes selon des critères de compétence relatifs au registre et à la langue qui excluent ceux qui ignorent les langues officielles européennes. L'étude suggère en outre que ces groupes ou sphéricules (Gitlin 1998) constituent des communautés discursives au sens de Watts (1999), c'est-à-dire des ensembles d'individus dont les pratiques discursives révèlent des intérêts, des croyances et des objectifs communs. Enfin, nous soutenons que la visibilité de tous ces groupes exige l'ouverture de la sphère publique à divers discours (Fairclough 1999, 2006), indépendamment de la façon dont ils se matérialisent. Ainsi, la contribution des personnes dont les répertoires linguistiques n'incluent pas les langues européennes ne sera ni nécessairement ni exclusivement rédigée dans des termes linguistiques. Une conséquence est une perte d'hégémonie de la part des langues européennes.

\section{Introduction}

In his much commented upon book, The Structural Transformation of the Public Sphere, Habermas describes the public sphere (PS) as an open domain of free conversation directed toward pragmatic agreement, and he characterizes it on the basis of two variables: the state, and the private community of citizens engaged in public deliberation with the aim of influencing the action of the state. Discourse is considered as essential for the participation of the citizenry in the public debate which, crucially, is supposed to take place in a society that happens to be homogeneous from the point of view of language. Agreement obtains exclusively through 
argumentation and may be reached not only on (what may be) matters of common or public concern but also on the way to deal with them. The main aim of this paper is to discuss the relevance of language and discourse in a genuinely multilingual context as is sub-Saharan Africa (henceforth Africa), and to assess the impact that language diversity may have on the dynamics of the public space, as well as the degree to which it may impinge on its relation with the African state.

We intend to show that whereas linguistic practices reveal evidences of abundant and multifarious cases of code-switching and code-mixing, the discursive practices and, more generally, the complex dynamics that characterize the public debate in this context are determined by sociolinguistic factors such as 'elite closure' and strategic language or register choice. Language diversity thus breaks up the public space into multiple small fragments which correspond to different groups, the two most important of which are distributed along the divide between the African languages and the exogenous (generally European) languages spoken in each country. The latter (or sphericules in the sense of Gitling 1998) are constructed around the European language spoken in the country and, as such, exclude those individuals who supposedly lack competence in that language or the register typically associated with it (or claimed as such) and, moreover, constitute a discourse community, i.e., a set of individuals whose discursive practices reveal interests, goals, beliefs, and, above all, rhetorical strategies that are common and exclusive to its members. The other sphericule, associated with African languages, has to do primarily with linguistic practice as well as discursive and rhetorical strategies which are typical of the traditional realm.

However, because of the prominence of the sphericules associated with the European languages, two groups of speakers are kept invisible in the public space: the individuals whose linguistic code is a mixture of some of the languages which coexist in a country and, to a lesser extent, those whose repertoires are limited to African languages. We argue in this respect that the visibility of such groups, necessary in any inclusive PS, requires the openness of the public space to diverse types of message, independent of the way and the linguistic code in which they materialize. One interesting consequence of the discussion has to do with the correlation which exists between the visibility of these speakers and the disempowering/disempowerment of the European languages which, to some extent, may favour 'linguistic convergence' in the context of public discussion.

Language diversity has thus the effect of adding a great deal of complexity and tension to the interaction of the PS and the state, besides accounting for linguistic and/or rhetorical strategies, commonly observed in public discussion 
within our context, which tend to blur all that may be considered proper to argumentation as much as they lend authority and even power to the individuals who use them. From this point of view, language plays a complex and crucial role in relation to the African public space, in part because of its social bracketing effects. On the one hand, it is a matter of concern for all citizens as well as for the state. On the other hand, and more generally, it is one of the vectors of the socio-political dynamics subsumed in the PS, since it is difficult to imagine the argumentative interaction without language (Wright 2008; Ejobowah 2001). Furthermore, a linguistic PS may be seen as a metaphor for such dynamics: a site which reflects the tensions and contradictions which characterize the socio-political landscape typical of the African states and the African PS in general.

The paper is organized as follows: Firstly, we intend to contextualise the public sphere by discussing some important differences between the way it has evolved in Europe and the public space as it unfolds in the context of African states. We then focus on the linguistic dimension of the public sphere and the internal organization and dynamics that characterize it in the African context. The last section deals with the discourse communities and their communicative practices, as well as the impact they have on the sociopolitical processes characteristically observed in Africa. We conclude by underlining the relevance of the communicative strategies adopted by the masses for their own empowerment as well as for the emergence of a PS in the African context in general before we briefly discuss the role of the state with respect to the effects of such strategies on both public discourse and argumentation.

\section{Contextualising the Public Sphere}

As described by Habermas, the PS was originally associated with the emergence of a new social class whose existence would suppose radical changes in the structure of the society and its relations with the state in the European context. In general, what characterises such a social group are contextspecific features relating to its internal composition, its aims and activities and the way it carries them out, as well as its relationship with the state and society in general. Accordingly, the topography of the PS results from the complex (and often inconsistent) way in which these features are articulated in the context considered in each case. In this section, we will discuss some of such features with reference to the European and the African contexts.

The Relevance of Affluence and Literacy in the Constitution of the PS The PS was originally constituted as a discussion group in which dialogue and argumentation prevailed. Habermas (1989:36) describes it as a space 
within which status was disregarded altogether, areas that until then had not been questioned were problematized, and 'the issues discussed became "general" not merely in their significance, but also in their accessibility: everyone had to be able to participate'. The relevance of argument, dialogue and agreement for the functioning of the PS suggests that it was an open space in whose activities any human endowed with reason could participate. In practice, however, only individuals pertaining to two apparently different social strata composed the original PS. In effect, many types of requisites, including affluence and literacy, constrained such a space, as they determined who could be a member of this group. According to Habermas:

[...] education was the one criterion for admission - property ownership the other. De facto both criteria demarcated largely the same circle of persons; for formal education at that time was more a consequence than a precondition of social status, which in turn was primarily determined by one's title to property. The educated strata were also the property owning ones (1989:85).

Thus, although the PS was accessible in principle to every citizen, given the centrality of reason and the irrelevance of (social) status, in practice it was a very exclusive community. Moreover, as underlined by Habermas, the sets of individuals that were part of that community were largely coincident, at least at the time of the emergence of the PS, when 'the educated strata were also the property owning ones'. Social status had not lost all of its relevance, but affluence and education appeared to be more intimately related to the new social class. In this sense, the original European PS was largely constituted by literates, bourgeois traders - literate or not - and only marginally by nobles.

The complexities of the socio-political dynamics that are typical of the African countries make the PS much more difficult to characterise in this context. The emergence of the modern African states supposed the superposition of a traditional and a modern realm associated, respectively, with ethnic groups and the state. In this sense, Africa - as described by Ekeh (1975, quoted in Joseph 1999) - presents two publics: 'one derived from the colonial superstructure and the other from a "deeper" African communal structure'. With respect to the latter, Joseph (1999:241) underlines that 'the participatory and communal elements that were central features of Athenian democracy are also constitutive elements of many African societies'. The markedly deliberative tendency of the PS in the traditional African realm is reflected still more clearly in Nyerere's notion that African democracy rests on individuals 'talking until they agree'. ${ }^{1}$ What does not seem so clear is the way agreement may be reached in the context of a PS accessible to all, whether by means of argument, authority or power, particularly in cases in 
which a mechanical majority and representation are deemed irrelevant. As for the colonial superstructure and the state that has resulted from it, they are intimately related to the emergence of new social strata which, also, has to do with education and affluence, and whose existence has supposed radical changes in society. The topological differences discussed below explain some of the disparities observed between these two public spaces.

The first of such differences has to do with the bourgeoisie as a social class. Whereas the changes related to the African modern state owe nothing to an African bourgeoisie, non-existent at the time of the state's emergence, the existence of the PS is difficult and even impossible to imagine in absence of the bourgeoisie in Europe. ${ }^{2}$ This fact accounts for the relevance of literacy in modern Africa where, clearly, it has been a precondition of social status and affluence. We thus observe a radical transformation of the society, as individuals are differentiated on the basis of an exogenous language and, more specifically, the knowledge of that language. The second difference is relative to the linguistic complexity of the public space. In effect, the linguistic diversity which characterizes African states eludes the idealized communicative community on which Habermas's reflections are based, and adds a great lot of complexity to the interaction of the PS and the state. In each country, many endogenous languages compete with different varieties of exogenous languages and with codes that result from the mixture of the former. In this sense, language may hinder access to the PS, in addition to barriers such as literacy, sex and affluence that also prevailed in Europe (Fraser 1992). Because of its very specific relevance in the African context, language appears to be, along with literacy as we will see, a crucial variable in the emergence of the PS. Other factors, centred on the relation of the PS with the state and with society in general, are the focus of the next sub-section.

\section{The PS and Socio-political Power}

Literate individuals in Africa, like bourgeois and educated people in Europe, considered they had a particular status that positioned them above all other citizens. In the European context, such people formed a very specific imagined community in the sense of Anderson (1991). In Habermas's (1989:37) terms, this community 'did not equate itself with the public but at most claimed to act as its mouthpiece, in its name, perhaps as its educator'. This allowed them to claim a privileged social status from which they could think and speak in the name of the masses and, by way of consequence, identify their own interests and concerns with those of the citizenry, or ignore the latter altogether, as many discussions of Habermas's work have shown (Habermas 1989:87-88; Fraser 1992 and, for recent discussion, Goode 2005). It is in this sense that one may characterise the members of both groups as 'educated 
and powerful citizens [who] were supposed to form an elite public [...] whose critical debate determined public opinion' (Habermas 1989:137). This exhausts the commonalities that exist between these two groups, in contrast to the multiple differences observed in their relation with the state and with society in general.

As observed before, the main aim of the political activity of the original PS in Europe was to influence the interaction of the state and civil society. To this end, it had recourse to reason and to argument, that is, to rationalcritical public debate, an art which 'the bourgeois avant-garde of educated middle class learned [...] through its contact with the "elegant world" generally associated with the courts of nobles' (Habermas 1989:29). Such an art consisted not only of discursive strategies related to argumentation, even though, supposedly, the outcome of the debate depended exclusively on argument, and agreement was reached through persuasion. It also implied certain specific attitudes on the part of the discussants whose status as members of the PS made them equals. In this way, another important feature of the European PS, namely the idea that human beings share a common quality, qua humans, made its way first in the private debates on literary and then on political matters. ${ }^{3}$ The combined effects of the discursive interaction of the members of the PS and the way the citizens were conceived account to a large extent for the many transformations undergone by the PS. One such transformation has to do with representation, and the other with agreement. With reference to the latter, Goode (2005) stresses that 'unforced consensus [...] associated with the rational-critical debate' has the virtue of transforming the PS into a 'site for the organisation of resistance and renewal as much as it is an arena for the mobilisation of domination and legitimation'. ${ }^{4}$

On the other hand, the so-called native language was an object of major preoccupation for all those who were part of the European PS, not only for its centrality in the debate but also because, to a large extent, it mediated the universality of the human condition. This was the case, for instance, with German societies (orders, chambers and academies, among others) which interpreted the native tongue as 'the medium of communication and understanding between people in their common quality as human beings and nothing more than human beings' (Habermas 1989:34).

Summing up, then, in their attempt to achieve consensus on the basis of persuasion, the members of the original European PS trusted reason, argument and the universality of the human condition or the equality of the citizens, not authority nor coercion. Despite the bias inherent in the claims of the elites, this ultimately had the effect of bringing them nearer to a (more) universal focus in their demands to the state. 
As already observed, the African context consists of two very dissimilar realms: traditional and modern. Due to the disparities between them, the access of individuals to modern education implied that on the one hand they acquired competence in a European language whereas, on the other hand, they distanced themselves progressively from the endogenous linguistic codes known or available to them. Seen in this light, literacy not only brought power and privilege, it also supposed - to some extent - estrangement from one's own (cultural and linguistic) community, an inconvenience unknown in the European context. An interesting consequence is that, although educated Africans claimed to be the voice of 'those who are not listened to', they could not represent (at least not as fully as the members of the European PS could do) the masses, in part because they were not familiarised with their concerns or simply ignored them. Likewise, the fact that the elites had a vested interest in protecting their status and privileges made it rather difficult, in spite of their claims, for their concerns to coincide with those of the public in general. Moreover, inasmuch as in the African context representation was not so much associated with common concerns as with individual interests, it could only stand in contradiction to the ideal of equality of all citizens and to the discursive practices associated with the Habermasian PS. In a context in which the art of rational-critical debate is neither learned nor cultivated, and representation has nothing to do with peer scrutiny nor with the common interests of the citizenry, the question arises as to whether consensus may be achieved and, in the affirmative case, how agreement obtains.

Turning now more briefly to the relation of these groups with the state, the fact that they are imagined communities does not strip them of the power they may have in correlation with their independence. The crucial difference between both groups is that whereas African elites emerged within the apparatus of the modern African state and were primarily state employees, the bourgeois PS 'arose historically in conjunction with a society separate from the state' (Habermas 1989:127). Moreover, the separation presupposed by the bourgeoisie was such that the PS, 'made up of private people gathered together as a public and articulating the needs of society with the state, was itself considered part of the private realm' (Habermas 1989:175-176). The power associated with this position of the European elites accounts for the fact that they claimed a PS regulated against the public authorities. As Goode (2005:5) observes:

[...] struggles over economic production and trade saw an increasingly confident 'private sphere' starting to erode the omnipotence of the state. A nascent bourgeoisie was carving out its independence and building a 'civil society' based on private commerce. 
Thus, far from depending on the state, European elites defied it, even though the confrontation did occur only when they explicitly and openly assumed a political role, that is, once the PS was consolidated. According to Habermas's (1989:35) narrative, such a 'coming together of private people into a public was [...] anticipated in secret, as a public sphere still existing largely behind the closed doors' ${ }^{5}$

In contrast, all members of the African elite depended on the state, in the sense that they were necessarily part of its structure, either as politicians, employees of the administration or both (see Bayart 2008 [1981], among others). This, together with the considerable power of the state apparatus in Africa, accounts for its tendency to strongly permeate civil society.

\section{The Changing Topography of the African Public Sphere(s)}

The European and African language divide opposes two realms which show important differences in their internal topography and dynamics: the fragmented traditional groups which coexisted in a given place and the modern state formed by many such groups. Generally, traditional societies corresponded to small groups of people whose members knew each other and carried on their intense interaction through spoken language. In terms of political culture, they tended to adopt very specific strategies in the assessment and solution of conflicts, which consisted basically in the so-called palabre. According to Beti \& Tobner:

L'usage de la palabre suppose non seulement l'existence des conflits, assumés en tant que tels, mais l'aménagement millénaire de procédures visant à retarder la décision aussi longtemps que possible afin que le plus grand nombre possible de membres du groupe soient informés des données du débat et puissent y prendre part (1989:91).

[Recourse to 'palabre' implies not only the existence of conflicts, taken as such, but also the millenary development of procedures aimed at delaying the decision to be taken as long as possible so that the largest possible number of members could be informed about the issues discussed and partake in decision-making.]

Supposing that the debate was open to the extent of what Beti \& Tobner call 'libre parole collective', one may consider participation and deliberation as the most relevant aspects in the internal dynamics of these groups. However, this does not answer the question about the way in which consensus was reached, since it cannot be inferred on the basis of the dynamics typical of the palabre alone. The fact that agreement was the outcome of deliberation more than open discussion suggests that decision-making tended to result from accommodation. The latter is considered by Appiah (1992:129 ff.) as 
an essential feature of traditional societies. It is a 'general process [...] necessary for those who are bound to each other as neighbours for life', and its main effect in conversation is the avoidance of a style that is generally considered aggressive in this context. Convivial strategies tend to prevail in traditional societies, which are typically non-literate, and accommodate well to orality and figurative language, a language which is heavily indexical, metaphorical and, above all, context-dependent. Crucially, the style avoided in this context involves precisely the strategies that define the internal dynamics of the European PS, viz., to disagree and to argue.

The modern realm sets the state against civil society and includes much more of the imagined communities described by Anderson (1991). The members of civil society divide into two main groups: educated and nonliterate individuals. The former demonstrate characteristically spoken and written competence in the official language of their country, generally a European language and, also, a variable degree of estrangement with respect to the African languages. The reverse occurs with non-literate citizens, although an increasing number of them, generally young urban dwellers, tend to use codes that mix European and African languages, or a popular variety of the official European language. This fact does not seem, however, to make any difference between these two groups as far as the deliberative aspects of the PS are concerned; for educated as well as non-literate individuals coincide in avoiding the adversarial style which is so characteristic of the European PS, as they consider it aggressive to disagree and even to argue. ${ }^{6}$ This does not mean that critical debate is absent from the African context. What we wish to underline is that it proceeds in a different fashion and with different effects, as discussions tend to adopt different profiles depending on the context, the matter debated, and/or the other discussant(s). In contrast, the rational dimension has scarce prominence in all types of space but the intellectual milieu, in which recourse is had in principle to reason when dealing with so-called scientific matters. ${ }^{7}$ In any case, the binding effect of the debate is not as strong as in Europe, either on the discussants or at the public level in general. It may thus be said that the debate culture delimitates one single space, in contradistinction to the space associated with social status, and to the language divide discussed above.

Leaving aside factors such as sex, class or ethnic group, we thus have different spaces which overlap partially and not always in a consistent fashion. The asymmetry between the discursive sphere and the other kinds of space raises once more the interesting question as to how agreement obtains in African societies. This question comes in two parts, the first of which has been answered briefly above. Agreement is reached in part through 
accommodation, that is, the fact that one of the interlocutors does neither argue nor disagree. However, and this is the second part of the answer, this effect can be obtained only by means of very specific discursive strategies which characteristically are not based on arguments nor, more generally, on reason. Thus, whereas in the European PS public debate may be seen metaphorically as a fight in which reason and arguments are the only weapons allowed, in the African context what prevails are strategies which make possible the 'defeat of the opponent(s)' without the necessity of a better or stronger argument. An art that enables to 'vaincre sans avoir raison', as one of the characters of the novel of Hamidou Kane, L'Aventure ambigüe, puts it so emphatically with respect to (the 'school of) the White Man'. In so far as, for agreement to be reached people do not have to concede to reason, they have to bow to something else. We intend to show in the next section that the strategies that are more recurrent in this respect have much to do with language diversity and that, as one of their most significant effects, they tend to make it disproportionately relevant, in view of the sociolinguistic dynamics typical of this context.

\section{The Linguistic Public Sphere}

\section{Language and Socio-political Dynamics in Sub-Saharan Africa}

The diversity that is characteristic of Africa from the linguistic point of view owes much to the history of the continent, considered by many as the multilingual space par excellence. The socio-political dynamics typical of the pre-colonial period explain the large amount of indigenous languages which exist in any African country, whereas the process of colonization has meant, besides the imposition of an exogenous language, the intense interaction of multifarious language communities whose members have had to elaborate multiple and complex strategies in order to intercommunicate with, as a result, the enormous capacity of sub-Saharan Africans to flexibly adapt to disparate and variable sociolinguistic environments (Fardon and Furniss 1994). The most pervasive manifestations of this capacity are code mixing and code switching (Blommaert 2007). However, the fundamental divide from the sociolinguistic point of view opposes the citizens of a country on the basis of their linguistic repertoires and, most specifically, of their competence in the European language. Besides being the official language in the country in which it is spoken, the European language is generally associated with rational modernity, as well as with symbolic and economic power, in contrast to African languages which not only are marginal from the political, symbolic and economic point of view, but are also associated with tradition, conceived in opposition to development (Ambadiang 2005; Chumbow 2005). 
The codes resulting from mixing processes in which these two types of languages are involved tend to be overlooked in scientific reports on the sociolinguistic situation of the African countries and are largely ignored in the political agendas of the African governments. This occurs contrary to facts, since all citizens in these countries concur to a greater or lesser extent in code mixing, and given the increasingly generalized use of some of the codes that have resulted from mixing processes, specifically those based on European languages. Both tendencies are so widespread that sociolinguists tend to characterize African multilingualism as typically associated with mixing, in contrast to the idea of language segregation subsumed in the European conception of multilingualism (Makoni \& Meinhof 2003; Mugane 2006 and Blommaert 2007, among others). ${ }^{8}$

The invisibility of the mixed codes is of great interest for different reasons. Their absence from the scientific agenda is due to the fact that linguists tend to prefer so-called institutionalized languages as their objects of study. Their occultation in the political agendas is strategically related to what MyersScotton, following Max Weber, has dubbed 'social closure'. In effect, by stating that the popular (or mixed) variety of the European language used in a chosen country bears no identity relationship to that language, the (political or cultural) elite of that country strategically close off the access to their social class, thus hindering the social promotion generally associated with the European languages in this context, in order to maintain their privileges. We are thus told that a very small part of the citizenry, generally only the elite, display spoken and written competence in the corresponding European language. Lastly, from the social point of view, mixed codes tend to be associated with urban environments and more specifically with urban youth (cf. Ewota 1986; Herbert 1992, among many others). Their speakers, typically, lack both the power that characterizes the speakers of the European language, and the seal of authenticity which results from the association of the African language with tradition. In the light of the above, the relevance of these codes can be stated only in the case where their increasing expansion and the number of their speakers are taken as the crucial factors, which gives cause for the inclusion of these codes in the scientific, political and social agendas. If, as Mazrui (1996) and Makoni et al. (2003) emphasize, African languages should be privileged in the political and social realms because of the correlation that exists between their institutional use, democracy and development, it seems necessary to extend these privileges to the codes that result from mixing processes. ${ }^{9}$ Moreover, the inclusion of these varieties in the socio-political agenda has very interesting implications for both the topography and the internal dynamics of the African PS, as discussed below. 


\section{Communicative Practices and Agency}

Whereas communication has to do in general with linguistic and cultural competence, communicative practices are of special relevance in a context in which, as is the case with sub-Saharan Africa, social categorization is based essentially on linguistic and/or cultural behaviour (Makoni \& Meinhof 2003). There is a strong correlation in this context between the asymmetries which are apparent among members of a given group (ethnic or otherwise), from the linguistic and cultural point of view, and their tendency to linguistic and cultural accommodation. Speakers' linguistic repertoires vary largely as to the number and types of languages included in them, whereas language use oscillates between codes that exist separately from others in linguistic atlases, i.e., institutionalized codes, and mixed codes (Blommaert 2007). The results of the possible combinations of the languages available are enormously varied, even though only a few of them solidify into specific codes. However, in so far as such variation is not made use of without purpose, one may associate it with choice and, more generally, with agency. In this sense, it may be said that language learning and language use do not only suppose a cognitive burden but also the capacity of agency, as evidenced in the attitudes of speakers such as, for instance, those observed by Moreau (1994) and Canut (1996) in Senegal and Mali in relation to Wolof and Bambara respectively:

(a) 'Je parle leur langue pour faire des affaires avec eux, pas parce que ça m'intéresse' (Moreau 1994:86).

[I speak their language only out of the need for doing business with them, not because I have any interest in it.]

(b) 'Je garde mon accent, comme ça on sait que je suis peul' (cf. Canut 1996:73).

[I keep my accent, in this way everybody knows I am Fula.]

(c) 'Je ne connais que le nom des condiments pour faire mon marché' (ibid).

[I know nothing but the names of the condiments in order to do the shopping.]

(d) 'Je n'ai jamais appris cette langue, je n'en ai pas besoin' (ibid).

[I have never learnt this language, I do not need it.]

We suggest that attitudes such as those just mentioned, ranging from the ambivalence of (a-c) to the distance subsumed in (d), do not concern languages of wider communication only. Rather, they may be observed with any linguistic code, depending on the way a given speaker conceives his relationship with that code. 
As for accommodation, we owe a very interesting illustration to Finlayson \& Slabbert (1997), who depict communicative interactions typical of the African context by means of the metaphor of a bridge that the interlocutors cross in such a fashion as to 'meet halfway'. This means that in this context, communicative processes are heavily influenced by the speakers' disposition to cooperate, through negotiation and adaptation, from the linguistic and communicative point of view. Once interlocutors negotiate, on the basis of their linguistic repertoires, the languages that are most useful for intercommunication, boundaries between the latter tend to collapse and multiple mixed codes arise.

There thus seems to be a strong correlation between agency and accommodation: people tend to feel free in the way they learn and use any language because (they know) that their interlocutors, whether they are native speakers or not, are disposed and willing to make up for their flaws. Because the speakers' disposition to cooperate makes intercommunication possible, language diversity may not impede the constitution of a public sphere. However, the contrast observed between the communicative adaptability that uniformly characterizes the linguistic PS and, on the other hand, the internal fragmentation of society suggests that intercommunication (or the ability to communicate) is a necessary but not sufficient condition for the constitution of a socio-political PS, for reasons to be discussed in the next section (cf. Antonsich 2008; Ipperciel 2008).

\section{Discourse Communities and Rhetorical Strategies}

Although discourse communities may be described in terms of individuals whose discourse practices reveal common interests, goals and beliefs with respect to a specific concern or object of study (Watts 1999)), some communities may share any of these features but discourse. In our context, the problems related to language diversity concern both the elite and the masses which, from the point of view of their discursive practices, constitute different types of discourse communities. Furthermore, the messages subsumed or implicit in the communicative interactions of the latter may be linguistic or not (Carrithers 2005). Whereas the masses consider both the mixed codes and the individual (European and African) languages involved in their structure relevant for communicative and, more generally, for social purposes, the discussion among the elites is crucially based on the opposition of (European and African) languages. Thus, the two types of discourse which tend to prevail among modern elites are elaborated by so-called nationalists and pragmatists. The former consider the promotion of the African languages as a sine qua non of a genuine independence of African countries, supposing that it, moreover, favours the decolonisation of the mind and the 
integral development of the African masses. In contrast, pragmatists tend to see the European languages as more efficient instruments for the development of the African countries. ${ }^{10}$

These discourse communities are consistent with the (partial) linguistic spheres, or sphericules, described above as spaces of exclusion, particularly for the members of the subaltern sphere(s) associated with all but European languages. However, as already suggested, the exclusion can also be based on other factors which convert themselves into crucial rhetorical assets which may allow one to win without the necessity of adducing arguments. The power of exclusion or social bracketing of language accounts for the tendency to associate such rhetorical strategies with language use, as well as for the relevance of such strategies for the outcome of debates and discussions. The rhetorical strategies of interest for our discussion will thus have to do with language and register choice. Language choice is relevant mostly in cases in which different languages are involved because discussants (claim to) have divergent linguistic repertoires, whereas register (and sociolect) choice occurs when the discussants share the language in which the debate unfolds. Many scenarios may be envisaged here, depending on the language to be chosen, the status of the discussants who choose it and that of their interlocutor(s). We can only broadly sketch some of them here, focusing on the dynamics of public debate and the strategic uses of the languages available to each discussant. In the Table below, only such uses are indicated explicitly.

Strategic Uses of Languages in Public Debate

\begin{tabular}{l|l|l|l}
\hline & European language & African language & Mixed language \\
\hline Elites $>$ Elites & & & \\
Elites $>$ Masses & A & B & \\
Masses > Masses & & A & \\
Masses > Elites & B & & \\
\hline
\end{tabular}

Any debate opposes two discussants, one of which intends to cause a change in the other in terms of opinion, belief or behaviour (Carrithers 2005). The equal status of interlocutors in discussions based on reason and argument makes their roles interchangeable: any one of them may play the role of either the persuading agent or the persuaded. In a context in which debate is not exclusively, nor even mainly, based on reason and argument, language choice is crucial, for different reasons. Two types of context serve to illustrate the relevance of language choice for the dynamics of the debate. 
In the first context, corresponding to the A boxes in the table, an individual has recourse to a language other than the one used by the other discussants. In general, such a choice is exclusive to those who feel they are in a position of power: the irruption of such a code is as much advantageous to the individual who imposes it in a discussion as it is disempowering for the interlocutors due, mainly, to their scarce knowledge of that code. Thus, language choice appears to be doubly strategic: it is a manifestation of the power of the discussant which it also serves to confirm and reinforce. The outcome of the debate is thus decided on the basis of the status of the language used and, more specifically, on its association with the position of power of the speaker. This is what occurs when a member of the elite makes use of a European language with non-literate or semi-literate interlocutors, or when an (illiterate) elder has recourse to an African language among young men or modern elites who are less competent in that language. The fact that everybody acknowledges the association of such practices with authority and power, particularly in the case of the dominant languages, explains the register uniformity or homogeneity that tends to characterize public debates, as even individuals who typically use the popular versions of the European languages adopt the register of the elite (often with undesired and comical effects illustrated in many African novels and parodies of political speeches).

In the second context, corresponding to B boxes in the table, an individual who is not supposed to have much competence in a given code has recourse to it however. The effect has to do in this case with an attempt to avoid exclusion, since what is intended in such uses is to break down the language barrier erected by interlocutors who, incidentally, happen to be in a position of power.

Therefore, the discussants may have strategic recourse to a given language with the aim of gaining discursive authority or avoiding exclusion, though with different effects, given the asymmetrical power relationship which exists between the European and the African languages. From this point of view, one of the most interesting features of the Table has to do with the irrelevance of the so-called mixed codes. The fact that they cannot be put to strategic uses is consistent with their invisibility from the scientific and political point of view. The European languages are necessarily visible, whereas the African languages may be visible or not, depending on the speaker. As observed above, a significant consequence is the social irrelevance of the speakers of mixed codes, in spite of the fact that an increasing number of individuals use mixed varieties such as Pidgin English, 'français populaire', 'franglais', 'Frenglish', 'Sheng' or 'camfranglais' in urban settings, as replacement of indigenous languages or as a first language. 
This kind of exclusion has much more to do with power than with the sociolinguistic dynamics observed in the African context since, as underlined in the preceding sections, the use of code-mixing is generalized in the continent, though some speakers have recourse to this strategy more liberally than others. In so far as all languages present in this context share many of the features that are considered typical of mixed codes, particularly in informal communicative contexts, the linguistic landscape may be seen as a complex continuum with many different languages at its multiple poles and multifariously mixed varieties emerging between them. On the other hand, the ensuing difficulty to separate the codes makes it difficult to establish stable and consistent associations between any code and a given (social or discursive) function. Seen in this light, any strategic use of a European or an African language subsumes necessarily an intent to impose a particular variety of that language and, with it, a social order which is adequate to the interests of those who have such an intent. The above observations, together with the limitations of oral communication and the effects of accommodation, may help us get an idea of the complexity inherent in communicative processes of any kind, particularly those involving some form of discussion.

\section{The Linguistic Public Sphere(s) and the State}

From the observations adduced in the preceding sections, one might infer that two types of factor are mostly relevant for the constitution of a PS in our context. The first type is linguistic in nature, whereas the other has to do with the debate itself. As shown above, dynamics that are typical of the linguistic sphere may interfere with socio-political interactions, making it very difficult to learn and cultivate the art of public debate. The aim of the present section is thus to discuss the effects of sociolinguistic fragmentation in relation to the state and democratic representation.

Communicative Practices, Consensus and Democratic Representation Considered in relation to public debate, communicative practices have a procedural and a linguistic dimension. We have seen that from a linguistic point of view the predominant characteristic of the African context is linguistic accommodation, evidenced in code mixing as well as in the so-called 'convergence languages', i.e., languages whose expansion has implied more or less profound changes in their structure and their demography due to their non-native speakers (Mugane 2006). The democratic practices associated with these fragments of the linguistic sphere are thus in sharp contrast with what we observe in the contexts in which what we have dubbed strategic language use prevails. In opposition to language users who do not disrupt the tendency to inclusive participation in the linguistic PS, the individuals 
who make strategic use of language may be considered 'linguistic brokers', the effect of whose practices is to disempower their interlocutors by excluding them from the discussion, and even by cancelling it. This obtains mainly through processes of what may be called rhetorical bracketing and crossing (Rampton 1995). In the first case, an individual makes use of a dominant language or register with the aim of setting a difference that undermines the status of the interlocutors as discussants, given their rather scarce competence in that language or register. In the second, a speaker adopts the dominant language or register in order to ' $[. .$.$] appropriate, explore, repro-$ duce or challenge influential images and stereotypes of groups that they don't themselves [...] belong to' (Rampton 1999:421). Accommodation also occurs when the communicative practices are considered from a procedural vantage point, given the tendency of interlocutors to avoid the adversarial style typical of the Western PS. Consensus is reached on the basis of conviviality, not argument, with interesting consequences which have to do with what Mbembe (2001:11) calls simulacre, a relationship based on falseness and illusion. The inconsistency and fragility of such a relationship is emphasized by Sennett (1998, quoted in Johnson 2006:3) when he underlines that agreements forged through argument and debate are inevitably stronger and more enduring than ties shaped by mere convention or convenience. Besides the social effects just mentioned, agreement reached through argument has the property of empowering all the individuals involved in the discussion. Likewise, it induces each of them to reflect on the shared value commitments that can make their points of view and claims intelligible to the others (Johnson 2006:5). The consequences of concession based on convenience are much more difficult to assess, apart from its illusory effects. In this respect, Mbembe's (2001:111) observation concerning political authority fits the description of any kind of power relation in our context. The dynamics associated with power converge on an effect of simulacre which, according to Mbembe:

[...] does not increase either the depth of subordination or the level of resistance; it simply produces a situation of disempowerment for both ruled and rulers $[\ldots]$ although it may demystify the commandement, even erode its supposed legitimacy, it does not do violence to the commandement's material base. At best it creates potholes of indiscipline on which the commandement may stub its toe.

However, disempowerment is not the only negative effect of concessionbased agreement. In social terms, this kind of agreement cannot cast aside distrust and, by way of consequence, is more apparent than real and, above all, strategic. ${ }^{11}$ One of the purposes of simulacre is precisely the illusion of a 
total absence of conflict. This is what occurs with unstructured and seemingly deliberative formats which, though 'intended to foster enfranchisement, can in fact generate "false unity" or exaggerated impressions of harmony” (cf. Phillips 1991, quoted in Wayne 2000:180).

The illusory condition of this relationship is particularly evident in the fact that it is subject to constant, though tacit, contestation from below, and to a negotiation process that, besides being continuous, cannot avoid mistrust on both parts. This is why once applauding subjects may 'become a cursing, abusive mob' (Mbembe 2001:111). The ultimate consequence of conveniencebased agreement, however, is the de-humanisation of both poles of the relationship. Powerful members identify the interests and concerns of the group with their own, with the (apparent) effect of depriving the disempowered members of their liberty and subjectivity, whereas the latter comply only apparently with the dictates of the former. The group is thus fragmented along the line of power relations, and representation along such a divide can only be undemocratic, unless provision is made for making subjects' own voices heard.

Therefore, as was the case with language before, participation is not a sufficient condition for debate-based agreement. As underlined by Wayne (2000:187), 'it is too simplistic to assume that more participation would lead to greater democracy'. The focus of the next sub-section will be on the implications of the above observations for the participation of individual citizens in the political sphere.

\section{Linguistic Spher(icul)es and the Political Sphere}

African countries coincide grossly in their linguistic and political patterns. Although the territory that corresponds to each of them is enormously fragmented from the linguistic point of view, it is a markedly homogeneous arena in communicative terms. Moreover, the languages included in the linguistic space of each country, together with their corresponding sphericules, do not exhaust the communicative sphere. What the observations above suggest, thus, is that many of the problems which arise with respect to the participation of civil society in the political sphere in this context correlate with what we may call the 'language bias'. In effect, the political sphere is structured according to linguistic, not communicative, factors, as the marginality of the codes most heavily involved in communication, viz. mixed codes, makes it clear. From the political point of view, it has been argued that participation is not a sufficient condition for democracy as, by itself, it does not imply critical discussion or rational debate. Both factors, linguistic segregation and conviviality, may thus be considered as some of the most important barriers to the constitution of a PS of the type described by Habermas 
in Africa and, as suggested above, their effects can in no way be helpful for the participation of the masses in the political sphere. Because political participation favours the effective empowerment of the masses, it requires radical changes in the way both the communicative and procedural dimensions of public discussion are negotiated or even conceived. The following brief discussion of such changes will take the evolution of the Western PS as its starting point.

In his narrative on the European PS, Habermas considers its emergence as crucially dependent on affluence, literacy and power (related to the capacity of determining the actions of the state). Although he does not discuss the relative importance of each of these variables, one might consider literacy and freedom as the factors which affect most profoundly the dynamics of the PS, and affluence as a mere characteristic, though a most favourable one, of the context in which the PS happened to emerge. This is the case, besides its direct association with power. In comparison, the African PS cannot be related to affluence mostly because, due to their socio-political status, affluent people (who are in general also literate) seldom engage in public debates whose purpose is to control the state and whose effects have to do with the empowerment of the masses. The interesting implication here is that the unique locus of the public space in which the PS may emerge is among the masses. In this respect, sight should not be lost of the fact that the masses are the social strata typically associated with the codes of wider communication, the mixed languages, which happen to be marginal. Note also that the features that are characteristic of the Western PS in relation to its internal dynamics, its purposes, its discursive basis, etc., may be observed in this locus, though in a rather inconsistent way. The question thus arises as to the conditions in which these small fragments of socio-political space may evolve into the democratic arena that would correspond to the PS in African countries. The observation of the sociolinguistic and political dynamics that characterize some of these countries is highly illustrative in this regard.

As suggested above, part of these conditions relates to the medium of communication. The main change in this respect consists in the adoption of the 'communication bias' according to which the solutions adopted by the masses should be given primacy in public communication. Not only are the codes involved in such solutions widely used, as is the case with Swanglish and Sheng in Kenya (Mugane 2006), Wolof in Senegal (Ngom 2004), Portuguese in Mozambique (Stroud 2007), or with popular varieties of French and English in different countries, they may be also politically relevant. For instance, Stroud (2007:43) stresses in his study of the sociolinguistic dynamics 
typical of Mozambique, that 'The use of African languages also contributes more widely to the vernacularization and popularization, that is, democratization of Mozambican politics'.

The democratization of politics ultimately implies the empowerment of the citizenry. A multilevel linguistic sphere, inspired in the notion of 'segmented levels of public discourse' (cf. Beierwaltes 1998, quoted in Breidbach 2003:86), would be apt here, though we will consider only two such fragments: the level of public discussion and the level of scientific debate. The former would cover the space corresponding to the PS, in which matters of common concern may be openly discussed, the latter being circumscribed to circles of specialists and professionals. Likewise, the codes of wider communication, and more generally linguistic accommodation, would help to solve the problems that arise around the commonality of the debate language.

Other conditions, related to the debate procedure itself, have to do with the attitudes as well as the cognitive and psychological capacities of the discussants. Johnson (2006:5), for instance, alludes to the hermeneutical effort required of all members of the PS, whereas Wayne (2000:187) associates the political culture based on public debate with the necessity for the citizens to "consciously adopt the discursive attitudes of responsibility, self-discipline, respect, cooperation [...] necessary to produce consensual agreement' (cf. also Newman 2005a, b; Roberts \& Crossley 2004). Assuming consensus results from discussion and argument, such attitudes and aptitudes are mostly the result of a learning process, as stressed by Habermas in his account of the emergence of European PS. Interaction with other members of the community is crucial in the learning process, though the most relevant factor is literacy, as evidenced in the following statement:

In the sphere of civil society, vernacular literacy programmes have been used actively by rural women to create a private and gendered space for themselves as they no longer have to rely on male literacy brokers for help with their written communication [...] and are free to broach topics that were previously taboo (Stroud 2007:44).

These circumstances, which may be applied to other subaltern groups such as semi-literate urban youth, remind us of the tendency of the emergent European PS to reflect upon topics previously exclusive to the church or the state. ${ }^{12}$ Reading (and thus literacy) has, besides informing, the effect of making one part of an imagined community, which is very helpful for the adoption of the adversarial style that characterizes rational debate. In this sense Appiah $(1992: 131,133)$ stresses that 'literacy moves you toward universality in your language', whereas printing breeds 'the independence of minds'. 


\section{Conclusion}

The public sphere is a virtual space composed by smaller fragments differentiated on the basis of variables as disparate as the medium of communication, the social status or gender of its members, or its purpose(s), but whose internal dynamics are strictly coincident. The discussion above has shown that language is very important for the constitution and internal dynamics of any PS, particularly so in a context of considerable language diversity as is Africa. The linguistic PS is, by way of consequence, a crucial component of the (political) PS and, correlatively, a space in which the battle for the empowerment of the citizenry is fought. The fight is fundamentally between the groups of privileged and disempowered citizens. The former may be characterized as linguistic brokers who have developed social skills which allow them to make a strategic use of their linguistic competence. Though they have recourse to code mixing, as everybody does in this context, their claims are related to languages as traditionally conceived, that is, to institutionalized languages, typically associated each to a specific community of speakers and showing (supposedly) a very limited degree of loan structures, in contrast to mixed codes. From the communicative point of view, the status of these brokers is based on the competence they claim to have in one or more languages, that is, on symbolic (socio-cultural) capital which generally correlates with economic and even with political power. In accordance with their linguistic ideology, they conceive language use as a migration process across different languages separated by neat and clear frontiers. Moreover, their power position allows them to strategically impose on their interlocutors any of the dominant languages included in their repertoire. In contrast, the interactions in which the masses are involved tend to be associated with marginalized codes. In this sense, the masses are generally identified with trans-linguistic spaces, in which migration can only be partial, as though any speaker had (temporarily) a foot in each of the languages involved in a given interaction.

Although language diversity is a matter of concern for all, there is no debate between the two most important fragments of the public space - the powerful elites and the masses - which may be identified with two different linguistic subcultures, code-based and communication-based, respectively, the former of which is imposed on the masses. Moreover, as stressed above, any debate or discussion between individuals belonging to both fragments of the public space has something of a masquerade in the sense that, very often, the form of their messages does not adjust to their linguistic culture or to their claims in this respect. In this way, strategic language use reinforces the code-based culture which, in turn, explains the attention, frequently bordering on obsession, with which the form of the messages is dealt with in our context. As a result, form rather than content or arguments tends to 
be the focus of the interaction, since it is the factor which determines the outcome of any discussion. This has the effect of disempowering the masses: it deprives them of the linguistic code(s) they normally use and, as a consequence, it hinders and even impedes their participation in any form of debate. Therefore, a first step towards the diffusion of the art of open debate in the public space supposes that, on the one hand, primacy is given to the communication-based culture and, on the other, the linguistic brokers are disempowered by stripping strategic language use of the power associated to it and, hopefully, getting rid of it altogether. Once there is no space left for strategic language use, attention may (progressively) be focused on contents and arguments. Seen in this light, language, or more precisely communication itself, is an essential factor for the constitution of the PS.

However, communication is not a sufficient condition for the emergence of a PS. As discussed above, neither a common language, nor a communicative chain may make a PS emerge. For this to happen, specific attitudes and aptitudes are deemed crucial and moreover, as suggested before, many of them have to be learned. The most relevant of the former is the adversarial style, whereas literacy, undoubtedly the best start in learning such a style, is the crucial factor among the latter.

Finally, the discussion above shows that in spite of the diversity of historical and social conditions in which public spheres emerge in different contexts, they share a set of characteristics which have to do with communication (the capacity of their members to reach each other in communicative terms) and with debate. In so far as these characteristics are also essential features of any democratic space, we suggest that attention be paid to the masses and the solutions they elaborate in their way to the construction of (an) African PS. The master words here are empowerment and equality, though the reality to which they refer is heavily dependent on the state.

\section{Notes}

1. The description offered by Nyerere is consistent with the idea of a political system characterized by 'a commitment to the resolution of problems [...] through public reasoning'; see Cohen (1989) and Schmitter and Karl (1991), quoted in Joseph (1999) and, more recently Newman (2005a, b), Ejobowah (2001), Roberts \& Crossley (2004) and Wright (2008).

2. According to Bayart (2008 [1981]), 'Parler de "bourgeoisie nationale" paraît [...] prématuré, voire déplacé'.

3. '[...] social equality was possible at first only as an equality outside the state' (Habermas (1989:35).

4. According to Goode, 'due to the interests of the social actors implied and their asymmetrical power relations, it is difficult to seek to conceive the public 
sphere as homogenous, uniform, unidimensional and equitable or to treat it as the arena of unqualified "virtue" vis-à-vis authoritarian states or unrepresentative public authorities'.

5. 'The process in which the state-governed public sphere was appropriated by the public of private people making use of their reason and was established as a sphere of criticism of public authority was one of functionally converting the public sphere in the world of letters already equipped with institutions of the public and with forums for discussion', cf. Habermas (1989:51).

6. See Appiah (1992:130) for an interesting illustration and discussion.

7. Thus, one of the spaces in which debates are most frequent is bars (so-called 'bistrots') and palm wine drinking joints. However, discussions tend to be chaotic from all points of view and may turn into passionate, even violent encounters.

8. In this sense, most studies on African languages and sociolinguistics do not seem to avoid a monolingual or 'purist' bias, due mainly to the fact that they do not take into account the mixing processes which are so characteristic of communication in Africa.

9. This, notwithstanding the problems which arise with respect to collective and individual identity. Such problems will not be discussed here however.

10. See, for instance, Mazrui (1996) and, for recent discussion, Makoni et al., (2003), Chumbow (2005) and Wa Thiong'o (2005). Modern elites may thus differ from those traditional elites who strategically abide by tradition and African languages.

11. This may have to do with the fact that "power in Africa has long depended more on wealth in people than wealth in things, that is, more on the cultivation of social relations, and to attract and sustain subordinates through patronage and feeding of the social body', (cf. West, 2005; quoted in Stroud 2007:41).

12. Bayart (2008 [1981]), for instance, considers 'la catégorie des jeunes marginalisés par l'appareil de production capitaliste et vivant d'expédients' as 'la plus décidée à affronter le système de domination en place, parce qu'elle n'a rien à perdre, ni d'un point de vue "traditionnel" ni d'un point de vue "moderne".

\section{References}

Ambadiang, T., 2005, 'Política y políticas linguísticas en África', in Mbuyi Kabunda Badi \& Carlo A. Caranci, eds., Etnias, estado y poder en África, Vitoria-Gasteiz: Servicio Central de Publicaciones del Gobierno Vasco, pp. 101-145.

Anderson, B., 1991, Imagined Communities: Reflections on the Origin and Spread of Nationalism, London: Verso.

Antonsich, M., 2008, 'Linguistic Commonality between Universalism and Particularism: A Reply to Ipperciel (2007)', Nations and Nationalism, 14, 3, pp. 600-605.

Appiah, A.K., 1992, In My Father's House, Cambridge: Cambridge University Press.

Bayart, J.-F., 2008 [1981], 'Naissance d'une bourgeoisie africaine', Manière de voir', Le Monde diplomatique, 99, pp. 18-20.

Blommaert, J., 2007, 'Linguistic Diversity in Africa', in M. Hellinger \& A. Pauwels, eds., Handbook of Language and Communication: Diversity and Change, Berlin/New York, Mouton de Gruyter, pp. 123-149. 
Breidbach, S., 2003, 'European Communicative Integration: The Function of Foreign Language Teaching for the Development of a European Public Sphere', in M. Byram \& P. Grundy, eds., Context and Culture in Language Teaching and Learning, Clevedon: Multilingual Matters, pp. 81-91.

Canut, C., 1996, 'Dynamique plurilingue et imaginaire linguistique au Mali: entre adhésion et résistance au bambara', Langage et société, 78, pp. 55-76.

Carrithers, M., 2005, 'Why Anthropologists should Study Rhetoric', Journal of the Royal Anthropological Institute, 11, pp. 577-583.

Chumbow, B.S., 2005, 'The Language Question and National Development in Africa', in T. Mkandawire, ed., African Intellectuals. Rethinking Politics, Language, Gender and Development, London/Dakar: Zed Books/CODESRIA, pp. 165-192.

Ejobowah, J.B., 2001, Competing Claims to Recognition in the Nigerian Public Sphere: A Liberal Argument about Justice in Plural Societies, Lanham, MD: Lexington Books.

Ewota, J.I., 1986, 'Code-mixture: An Outgrowth of Urbanization and Multilingualism', Cameroon Tribune (15 October 1986, p. 15).

Fardon, R. \& Furniss, G. , 1994, 'Introduction: Frontiers and Boundaries - African Languages as Political Environment', in R. Fardon \& G. Furniss, eds., African Languages, Development and the State, London: Routledge, pp. 1-29.

Finlayson, J.G., 2005, Habermas: A Very Short Introduction, Oxford, Oxford University Press.

Finlayson, R. \& Slabbert, S., 1997, 'I'll Meet You Halfway with Language: Code-switching within ASouth African Urban Context', in M. Pütz, ed., Language Choices: Conditions, Constraints, and Consequences, Amsterdam: John Benjamins, pp. 381-421.

Fraser, N., 1992, 'Rethinking the Public Sphere: A Contribution to the Critique of Actually Existing Democracy', in Craig Calhoun, ed., Habermas and the Public Sphere, Cambridge, Mass.: MIT Press, pp. 109-142.

Gitlin, T., 1998, 'Public Sphere or Public Sphericules?', in T. Liebes and J. Curran, eds., Media, Ritual, Identity, London: Routledge, pp. 168-175.

Goode, L., 2005, Jürgen Habermas. Democracy and the Public Sphere, London: Pluto Press.

Habermas, J., 1989, The Structural Transformation of the Public Sphere: An Inquiry into a Category of Bourgeois Society, Cambridge: Polity Press.

Herbert, R.K., 1992, 'Language in a Divided Society', in R.K. Herbert, ed., Language and society in Africa. The Theory and Practice of Sociolinguistics, Witwatersrand: Witwatersrand University Press, pp. 1-17.

Ipperciel, D., 2008, 'Transcending Particularities through Communication: A Reply to Antonsich', Nations and Nationalism, 14, 3, pp, 606-612.

Johnson, P., 2006, Habermas. Rescuing the Public Sphere, London: Routledge.

Joseph, R., 1999, 'Democratization in Africa after 1989: Comparative and Theoretical Perspectives', in L. Anderson, ed., Transitions to Democracy, Columbia: Columbia University Press, pp. 237-260.

Makoni, S. \& Meinof, U.H. , 2003, 'Introducing Applied Linguistics in Africa', AILA Review, 16, pp. 1-12. 
Makoni, S., Smitherman, G., Ball, A.F., \& Spears, A.K., 2003, eds., Black Linguistics: Language, Society, and Politics in Africa and the Americas, London: Routledge.

Mazrui, A.M., 1996, 'Language Policy and the Foundations of Democracy: An African Perspective', International Journal of the Sociology of Language, 118, pp. 107-124.

Mbembe, A., 2001, On the Postcolony, Berkeley: University of California Press.

Moreau, M.L., 1994, 'Ombres et lumière d'une expansion linguistique', Langage et société, 68 , pp. 55-76.

Mugane, J., 2006, 'Necrolinguistics: The Linguistically Stranded', in J. Mugane, J.P.Hutchinson and D.A. Worman, eds., Selected Proceedings of the 35th Annual Conference on African Linguistics, Somerville, MA: Cascadilla Proceedings Project, pp. 10-21.

Newman, J., 2005a, 'Participative Governance and the Remaking of the Public Sphere', in J. Newman, ed., Remaking Governance: People, Politics and the Public Sphere, Bristol: Polity Press, pp. 119-138.

Newman, J., 2005b, 'Conclusion', in J. Newman, ed., Remaking Governance: People, Politics and the Public Sphere, Bristol: Polity Press, pp. 197-213.

Ngom, F., 2004, 'Focus on Africa: Sociolinguistic Changes in a Changing World', International Journal of the Sociology of Language, 170, pp. 95-111.

Rampton, B., 1995, Crossing: Language and Ethnicity Among Adolescents, London: Longman.

Rampton, B., 1999, 'Styling the Other: Introduction', Journal of Sociolinguistics, 3, pp. 421-427.

Roberts, J.M. \& Crossley, N., 2004, 'Introduction’, in N. Crossley \& J.M. Roberts, eds., After Habermas: New Perspectives on the Public Sphere, Oxford: Blackwell Publishing/The Sociological Review, pp. 1-27.

Scotton, C.M., 1993, 'Elite Closure as a Powerful Language Strategy: The African Case', International Journal of the Sociology of Language, 103, pp. 149-163.

Stroud, C., 2007, 'Bilingualism: Colonialism and Postcolonialism', in M. Heller, ed., Bilingualism: A Social Approach, Basingstoke: Palgrave Macmillan, pp. 25-49.

Wa Thiong'o, N., 2005, 'Europhone or African Memory: the Challenge of the PanAfricanist Intellectual in the Era of Globalization', in T. Mkandawire, ed., African Intellectuals. Rethinking Politics, Language, Gender and Development, London/Dakar: Zed Books/CODESRIA, pp. 155-164.

Watts, R.J., 1999, 'The Social Construction of Standard English: Grammar Writers as "a Discourse Community"', in T. Bex and R. Watts, eds., Standard English: The Widening Debate, London: Routledge, pp. 40-86.

Wayne, C., 2000, Activism in the Public Sphere: Exploring the Discourse of Political Participation, Burlington: Ashgate.

Wright, S., 2008, 'Language, Communication and the Public Sphere: Definitions', in R. Wodak \& V. Koller, eds., Handbook of Communication in the Public Sphere, Berlin/New York: Mouton de Gruyter, pp. 21-43. 